\title{
O ESTADO E AS ORGANIZAÇÕES DA SOCIEDADE CIVIL
}

\author{
Andrea Mustafa \\ Ex-presidente do Centro Acadêmico XI de Agosto \\ Diretora-fundadora do Instituto Pró-Ação pela Cidadania Jovem
}

\section{Resumo:}

$\mathrm{O}$ artigo aborda as relações entre Estado e sociedade, enfatizando as organizações da sociedade civil e seu papel de espaço de debate, que assegura a participação efetiva dos indivíduos nos âmbitos de discussão e decisão. Traz, ainda, considerações sobre uma possível nova esfera de poder que vem sendo denominada Terceiro Setor.

Abstract:

The author's study is about the relations between State and Society, giving emphasis on the civil organizations and their functions as a debate space which ensures an effective engagement of the individuals in public decisions. It also deals with, likely, a new sphere of power which has been called Third Sector.

Unitermos: sociedade, esfera de poder, Estado.

A sociedade civil é a conseqüência das condições de vida em uma comunidade, estabelecidas através do Iugar, da história e da cultura, a partir da articulação e formação de entidades entre os indivíduos. Esta é a noção de sociedade civil apresentada por Paolo De Carli, na obra Lezioni e Argomenti Di Diritto Pubblico Dell'Economia. ${ }^{1}$ Para seguir a mesma linha de raciocínio será assumida a noção de Estado introduzida pelo mesmo, qual seja a de "Stato-persona" (ou "Stato-governo" ou "Stato-apparato"). Aponta o autor, em suas notas, que a distinção entre Stato-ordinamento e Stato-apparato é a seguinte: o Statoordinamento identifica o ordenamento geral e originário próprio de sua formação e tem sua definição através de três elementos fundamentais: povo, território e poder soberano. Enquanto que o Stato-apparato identifica um sujeito em particular, no âmbito da comunidade em geral e do ordenamento geral e originário, assegurando a

1. Cedam-Casa Editrice Dott, Antonio Milani, 1995. 
realização de um fim que venha a ser considerado de interesse público e geral, em um determinado momento histórico.

A base teórica para a relação Estado e sociedade está na idéia do contrato social. Este, como uma ficção intelectual, permite que o ordenamento político seja pensado, sendo portanto um produto da "deliberação humana" As origens do contratualismo estão, essencialmente, no pensamento referente ao espaço político. Do pacto entre os cidadãos depende o próprio destino de toda a comunidade. Na obra Democracia na América, Alexis de Tocqueville, ao descrever as percepções obtidas frente ao espaço político norte-americano, pondera que 0 rumo da comunidade seria tomado de acordo com as decisões da própria, que possuía a cultura do associativismo muito presente. Sendo assim, o autor considera que as associações civis são as raízes da democracia, pois é através delas que os cidadãos aprendem a "arte" de se associar, e ainda a buscar os fins de toda a comunidade.

Sendo o contrato social um corpo composto de crenças, valores e idéias sobre o dever-ser da ordem social, é possível reconhecê-lo como um espaço de debate, de convergências e divergências de idéias, visando à concepção de um "novo pacto social para o século $X X{ }^{2}{ }^{2}$ Frente ao desafio de uma sociedade mais presente e com poder de decisão nos espaços públicos, Bernardo Toro considera como expressão máxima da participação a "possibilidade de criar a ordem em que se quer viver" E a idéia a ser desenvolvida adiante é que são justamente as organizações da sociedade civil que podem propiciar tal debate no país, através do setor surgido e composto por elas.

Perante a sociedade civil, o Estado pode ocupar um espaço maior ou menor, gerindo a sociedade ou limitando-se a reconhecer e controlar as múltiplas atividades destinadas a satisfazer os interesses coletivos. Há variadas peculiaridades a serem observadas na (re)organização do espaço público brasileiro.

$\mathrm{O}$ regime autoritário no país, vivido a partir da década de $60 \mathrm{e}$ acentuando-se nas duas décadas seguintes, gerou uma espécie de "estrangulamento" das formas de participação existentes, assim, vislumbrou-se como saída a valorização da comunidade, através de um trabalho de base (comunitário). 0 aparecimento de novos movimentos sociais aliado à multiplicação das associações

2. Bombal, Inês González. Palestra proferida na comissão temática no IV Encontro Iberoamericano do Terceiro Setor. Buenos Aires, 14-16 de setembro de 1998. 
de moradores, no período, foram fundamentais, tanto pelo aprendizado de uma "cultura de iniciativas não governamentais formada pela base" ${ }^{3}$ como para que fossem introduzidos novos atores no espaço público e, conseqüentemente, novas agendas de discussão.

$\mathrm{Na}$ década de 80 , somou-se às iniciativas referidas anteriormente a atuação das ONGs. Inicialmente, seus membros imaginavam ser, devido ao período repressor, uma solução provisória destinada a apoiar os movimentos sociais. Contudo, ao longo da década, as razões para a aquisição de um caráter permanente foram identificadas, dentre elas: a questão de não serem órgãos representativos, não necessitando portanto de jogos políticos e tendo seu valor dependente apenas das respostas aos serviços oferecidos.

Atualmente, o aumento das $\mathrm{ONGs}^{4}$ em termos quantitativos e qualitativos (no tocante à missão) advém da ininterrupta abdicação da força pública do Estado, ou melhor de suas funções públicas. O Estado abdicando de suas funções trouxe como consequiência um espaço entre ele e a sociedade, no qual os sujeitos individuais e coletivos se articulam para exercer tarefas tipicamente públicas.

"Quando esses interesses (de grupos) extrapolam os fins lucrativos, e não são estritamente governamentais, é criado um campo de sociabilidade política cujo caráter público expressa um potencial espaço público. Um autêntico espaço público, contudo, não é automaticamente assegurado senão com base em alguns pré-requisitos. Dentre eles, o de constituir a vontade de um grupo em fundar algo novo, um ato político fundador cuja transparência é assumida como condição prévia de sucesso dos interesses envolvidos. Desta forma não é por ser coletivo que se define exclusivamente o espaço público. Tal ação é pública, de forma complementar e

3. Fernandes, Rubem Cesar. Privado Porém Público: o terceiro setor na América Latina. - Rio de Janeiro: Relume-Dumará, 1994.

4. Civicus - World Alliance for Citizen participation - tem recomendado o uso da denominação Organizaçōes da Sociedade Civil. 
necessária, pela qualidade da ação política do grupo, $e$ dos interesses envolvidos" ${ }^{5}$

Pode-se dizer que presenciamos o surgimento de uma nova esfera de poder que atua sobre o Estado, contra o Estado e com o Estado. Este novo setor tem recebido a denominação de terceiro setor. Foi o antropólogo Rubem Cesar Fernandes que em 1985, através do lançamento do livro Privado Porém Público, iniciou o delineamento do terceiro setor. Independentemente das discussões já existentes acerca da própria denominação, a definição apresentada pelo antropólogo foi a seguinte: ${ }^{6}$

"O Terceiro Setor ${ }^{7}$ é composto de organizações sem fins lucrativos, criadas e mantidas pela ênfase na participação voluntária, num âmbito não governamental, dando continuidade às práticas tradicionais da caridade, da filantropia e do mecenato $e$ expandindo o seu sentido para outros domínios, graças sobretudo, à incorporação do conceito de cidadania e de suas múltiplas manifestações na sociedade civil" ${ }^{8}$

Em um texto mais recente, ${ }^{9}$ o autor destaca diversos pontos interessantes na prática do setor, sendo que dois deles estão diretamente relacionados à importância das organizações da sociedade civil na discussão acerca de um novo pacto social:

5. Arendt, Hannah. A Condição Humana.

6. O debate sobre o nome utilizado para designar o setor das entidades sem fins lucrativos não é de consistência vazia, "verifica-se que não existe uma identificação com o termo terceiro setor". Esta foi a conclusāo apresentada por Rosa Maria Fischer em seu artigo "Desafios da Parceria Governo Terceiro Setor" (1998).

7. Devido ao curto período de desenvolvimento do setor no país, as discussões que culminam no próprio nome do setor advém, além do citado na nota anterior, da confusão no tocante às organizações que compõem o terceiro setor. Hoje, diversas entidades de pesquisa incluem como membros do terceiro setor grandes Empresas, através da justificativa de que tais empresas incorporam um princípio de voluntariado corporativo.

8. Fernandes, Rubem Cesar. Privado Porém Público.

9. Idem. O que é o Terceiro Setor in Desenvolvimento Social Sustentado. 
Empresta um sentido maior aos elementos que o compõem. Através de suas ações recupera a discussão de determinados valores que há muito foram banalizados, como por exemplo, cidadania e voluntariado.

- Projeta uma visão integradora da vida pública, possuindo uma dinâmica que enfatiza a complementaridade, sem o Estado as ações sucumbiriam na anarquia, já que não são auto-regulamentáveis e sem o mercado perderia sua dinâmica e autonomia. ${ }^{10}$

O ordenamento jurídico incorpora a evolução citada através do reconhecimento do seguinte fenômeno: a aproximação dos campos do Direito Público e do Direito Privado, ou seja, a publicização do Direito Privado e a privatização do Direito Público, através de princípios adotados em cada um desses campos antes considerados incompatíveis. Surge, assim, uma determinada categoria, que não é estatal e não pode ser privada, mas que deve ser instituída e controlada pela iniciativa privada, tendo o Estado um papel de fiscalizador.

Sob a alegação de necessário estímulo à criação de organizações da sociedade civil e pretendendo atingir seu universo - o terceiro setor entrou em vigor a Lei n. 9.790 de 1999. Poder-se-ia imaginar que a lei vem na tentativa de regulamentar um espaço privado que deve ser publicizado, porém a lei toma um caminho inverso, tornando privatizado um espaço público.

A exposição de motivos da Lei n. 9.790/99 transmite, de certa forma, um discurso que supõe determinados benefícios a entidades que "atuam para $o$ benefício da sociedade em geral" deixando, contudo, implícita uma tentativa de delegação de determinados deveres do Estado.

Há que se diferenciar, conseqüentemente, as organizações criadas pela referida lei e a noção de organizações da sociedade civil assumida, nestas considerações, como espaços da sociedade civil destinados ao preenchimento do conteúdo democrático de um Estado, através das relações entre os indivíduos, de suas atuações, e também de suas cobranças, individual ou coletivamente.

10. Esta característica que me permite sustentar que o espaço das organizações sem fins lucrativos atua, não somente contra o Estado ou sobre ele, mas também com ele, na medida em que, atualmente, é corrente a formação de parcerias entre tais entidades e o setor governamental. Parcerias denominadas intersetoriais. 
Para que seja possivel, porém, transformar o terceiro setor num espaço de discussão é imprescindível, primeiramente, a formação de um grande grupo de reivindicação frente ao Estado, seja para que se garanta o mínimo (função do Estado de garantia da continuidade de um processo produtivo), seja para a busca de uma maior autonomia administrativa, visando a um maior reconhecimento e valorização em termos legislativos do setor em questão.

A perspectiva seguinte é a discussão de modelos para a própria esfera das entidades sem fins lucrativos. Há de se ressaltar que o terceiro setor também vem sendo tratado como a "esperança" de emprego neste fim de século, movimentando anualmente milhões de reais."

"Entre los individuos y el estado, están las asociaciones y las asociaciones son hoy más que nunca necesarias para preservar el lazo social, asegurar la integración, promover el sentido de pertenencia, resguardar esse umbral mínimo de derechos que nos permita reconocermos mútuamente como ciudadanos de una misma comunidad política" 12

Reconhecer as organizações da sociedade civil como espaços que permitem a abertura de novos canais de participação e ainda a ampliação efetiva da cidadania é o início para que o objetivo de desenvolvimento de um setor formado por tais organizações não anule os serviços que o Estado deve prover, ou preencher lacunas deixadas por ele. O Estado deve ser o "guardião da sociedade, impedindo os conflitos e a violência" contudo deve também ser o "promotore del benessere dei cittadini" (Paolo De Carli).

É a partir da busca da plena participação dos indivíduos nas decisões acerca de ações e políticas transformadoras que se almeja a cidadania plena, não apenas para um indivíduo, mas para toda a coletividade. Sendo assim, a

11. De acordo com dados do GIFE - Grupo de Institutos, Fundações e Empresas, composto por, aproximadamente, 43 entidades, foram investidos, em 1999, $\mathrm{R} \$ 447$ milhões. Além disso, o setor emprega $2,5 \%$ dos empregados do país, e ainda, acrescentando os postos relacionados à religião, 0 número sobe para 3,2\% (Estudo comparativo em 22 paises, realizado pelo John Hopkins Center for Civil Society Studies in Global Civil Society Dimensions of the nonprofit sector).

12. Bombal, Inés González. 
característica do terceiro setor de "perseguir concretamente um interesse que transcende aos interesses dos próprios componentes" é a que sempre deve sobressair, movendo-se no campo da assistência social, da saúde, da cultura, do meio ambiente, etc. Nunca ignorando, porém, as funções obrigatórias do Estado.

São Paulo, janeiro de 2000.

Bibliografia

BOMBAL, Inês González. Palestra proferida na comissão temático no Encontro Iberoamericano do Terceiro Setor. Buenos Aires, 14-16 de setembro de 1998.

Coletânea de Textos, $3^{\circ}$ setor Desenvolvimento Social Sustentado. - São Paulo: Editora Paz e Terra, 1997.

DE CARLI, Paolo. Lezione e Argomenti Di Diritto Pubblico Dell'Economia. CEDAM Casa Editrice Dott, Antonio Milani, 1995.

FERNANDES, Rubem Cesar. Privado Porém Público: o terceiro setor na América Latina. Rio de Janeiro: Relume-Dumará, 1994.

FISCHER, Rosa Maria, FALCONER, Andrés Pablo. Desafios da Parceria Governo Terceiro Setor. Artigo selecionado para apresentação no I Encontro da Rede de Pesquisas sobre o Terceiro Setor na América Latina e Caribe ISTR. Abril, 1998.

GRAU, Eros Roberto. A Ordem Econômica na Constituição de 1998. $3^{a}$ ed. São Paulo: Malheiros, 1997. 